\title{
Potentially Toxic Metal-Bearing Phases in Urban Dust and Suspended Particulate Matter: The Case of Budapest, Hungary
}

\author{
Péter Sipos ${ }^{1}$, Tibor Németh ${ }^{1}$, Viktória Kovács Kis ${ }^{2}$, Norbert Zajzon ${ }^{3}$, Chung Choi ${ }^{4}$, \\ and Zoltán May ${ }^{5}$
}

\footnotetext{
${ }^{1}$ Institute for Geological and Geochemical Research, Research Centre for Astronomy and Earth Sciences, Hungarian Academy of Sciences, Hungary

${ }^{2}$ Institute of Technical Physics and Materials Science, Centre for Energy Research, Hungary

${ }^{3}$ Institute of Mineralogy and Geology, Faculty of Earth Science and Engineering, University of Miskolc, Hungary

${ }^{4}$ Department of Earth Sciences, University of Bristol, United Kingdom

${ }^{5}$ Institute of Materials and Environmental Chemistry Research Centre for Natural Sciences, Hungarian Academy of Sciences, Hungary
}

\subsection{Introduction}

Airborne particulate matter (PM) has been widely associated with health disorders primarily due to its fine particles but also due to its toxic components (Kim et al., 2015). Recent attention has been focused on the characterisation of its very fine-size fractions (below $10 \mu \mathrm{m}$ ) due to their easy penetration to the innermost regions of the lung (Samet et al. 2000). However, particles with a diameter up to $100 \mu \mathrm{m}$ can be inhaled or ingested, and those below $32 \mu \mathrm{m}$ may reach the bronchial tubes (UNEP and WHO, 1992). Airborne particulate matter can be divided into two types: the urban dust sediment and the suspended particles (Remeteiova et al., 2007). Urban dust is created by particles with great sedimentation power, and their delay time in the atmosphere is very short, causing generally nearsource pollution. Suspended particulates, however, may travel great distances due to their small particle size, resulting in contamination far away from their sources. Both of these materials generally show significant enrichment in several potentially toxic elements in the urban environment. Thus, after sedimentation, these particles can also contaminate soils, groundwater, and even the food chain (Seiler et al., 1988).

Studies on the sources, compositions, and distribution of airborne PM components are necessary for their risk assessment of atmospheric quality, ecology, and human health. This is especially true for the urban environment, where population and traffic density are relatively high, and the harmful effect of airborne PM is expected to be significantly increased (Vardoulakis et al., 2003). Environmental risk assessment of metals associated with PM has usually been based on the analysis of their total concentrations. However, it is a poor indicator of metal bioavailability, mobility, and toxicity, because these properties depend on the geochemical association of the trace elements with the different components of the solid matrix (Dabek-Zlotorzynska et al., 2003). Unfortunately, there is no known universal analytical technique capable of identifying as well as quantifying all metal species present in airborne PM. Furthermore, owing to the chemical complexity, extremely small particle sizes, and typically small total sample sizes, such 
materials can pose significant problems for analysis (Huggins et al., 2000).

A combination of several direct mineralogical and indirect geochemical analyses, however, was found to be an effective tool to study the potential host phases of potentially toxic elements in the airborne PM (e.g. Sipos et al., 2012). The aim of this chapter is to support this finding through summarising the results of our study on the host phases of potentially toxic elements in urban dust and total suspended particulate matter from Budapest, Hungary, based on published data.

\subsection{Materials and Methods}

\subsubsection{Sampling}

Urban dust (UD) samples were collected according to the Hungarian standard using glass pots of $2 \mathrm{~L}$ containing $500 \mathrm{~mL}$ distilled water seasonally for two years. Altogether eight sampling pots were placed at the front and the back sides of a high building at 2, 9, 21 , and $33 \mathrm{~m}$ heights next to a very busy road. Dust and water samples were separated using vacuum filtering by a $2 \mu \mathrm{m}$ Millipore filter. The dust samples were separated from the filters in an ultrasonic bath. More details on sampling and the characterisation of the sampling site and the samples can be found in Sipos et al. (2014).

Total suspended particulate matter (TSP) samples were collected from the air filters placed in the air supply channels of methaneheated turbines in four thermal power stations. Altogether 11 samples were collected from four sampling sites close to industrialised areas. The filters were in use for between 3 and 15 months. Samples were removed from the filters mechanically, and the material was passed through a $0.5 \mathrm{~mm}$ sieve. More details on the sampling and the characterisation of sampling sites and samples can be found in Sipos et al. (2013a). TSP material collected from such filters was also found to be useful for studying metals' speciation because the mineralogical and geochemical characteristics of metals are similar to those of samples collected by conventional air samplers (Sipos et al., 2016).

\subsubsection{Geochemical and Mineralogical Analyses}

The total concentrations of major and potentially toxic elements (PTEs) in UD (Ba, $\mathrm{Ca}$, $\mathrm{Cr}, \mathrm{Cu}, \mathrm{Fe}, \mathrm{Mn}, \mathrm{Pb}, \mathrm{Sr}$, and $\mathrm{Zn}$ ) and TSP (Ba, $\mathrm{Ca}, \mathrm{Cr}, \mathrm{Cu}, \mathrm{Fe}, \mathrm{K}, \mathrm{Mn}, \mathrm{Ni}, \mathrm{Pb}, \mathrm{Rb}, \mathrm{S}, \mathrm{Sr}, \mathrm{Ti}, \mathrm{V}$, $\mathrm{Zn}$, and $\mathrm{Zr}$ ) samples were analysed by $\mathrm{X}$-ray fluorescence spectrometry from pressed powder samples (Philips PW2404 and Thermo Niton XL3 type spectrometers). Enrichment of metals in the samples was calculated by geoaccumulation indexes after $\mathrm{Ji}$ et al. (2008) using the data of the geochemical map of Hungary as geochemical background values (Ódor et al., 1997). Details of the chemical analyses can be found in Sipos et al. (2013b and 2013c).

Single (water extraction and aqua regia dissolution) and sequential (BCR method after Rauret et al., 2001) chemical extractions were also carried out on the TSP samples. The residual materials after the BCR extraction were subjected to a four-acid digestion, as well. Solutions of the single-step extractions were analysed by ICP-MS (Perkin-Elmer Elan 9000), whereas those from sequential extraction were analysed by the ICP-OES technique (Agilent 710) for the concentrations of $\mathrm{Al}, \mathrm{Ca}, \mathrm{Fe}, \mathrm{K}, \mathrm{Mg}, \mathrm{Mn}, \mathrm{Na}, \mathrm{P}, \mathrm{S}, \mathrm{Ti}$, $\mathrm{Cd}, \mathrm{Cr}, \mathrm{Cu}, \mathrm{Ni}, \mathrm{Pb}$, and $\mathrm{Zn}$. Details of the analyses can be found in Sipos et al. (2016).

The bulk mineralogical composition of the samples was characterised by X-ray powder diffractometry (XRD) (Philips PW 1710). Loss on ignition of the TSP materials was studied by thermogravimetry (MOM derivatograph). High-resolution transmission electron microscopy (TEM) and selected area electron diffraction analyses were carried out to analyse the mineralogy and composition of single particles both in UD and TSP samples (Philips CM20 equipped with a Noran energy dispersive spectrometer (EDS)). The chemistry and 
morphology of particles in the TSP samples were also studied by scanning electron microscopy (SEM) equipped with EDS (Jeol 8600). Details of the analyses can be found in Sipos et al. (2013c and 2014).

\subsection{Results and Discussion}

\subsubsection{Urban Dust (UD)}

\subsubsection{Metals' Enrichment}

The average concentrations of $\mathrm{Ba}, \mathrm{Ca}, \mathrm{Cr}$, $\mathrm{Cu}, \mathrm{Fe}, \mathrm{Mn}, \mathrm{Pb}, \mathrm{Sr}$, and $\mathrm{Zn}$ and their ranges (see detailed data in Sipos and May, 2013b) in the UD samples were found to be similar to those as found in other Central European towns (e.g. Krolak, 2000). On the basis of the geoaccumulation indexes of the studied metals, two main groups were distinguished, which could be also subdivided further (Figure 28.1).

The first group was that of $\mathrm{Ca}, \mathrm{Fe}, \mathrm{Mn}$, and $\mathrm{Sr}$, showing no significant enrichment in the dust. Within this group, $\mathrm{Ca}$ and $\mathrm{Sr}$ showed moderate enrichment in some cases. These latter two metals are considered to be the marker of construction dust in urban areas on the one hand (Ji et al., 2008), while on the other hand, their slight enrichment can be also due to the dolomitic geological environment. Although these elements are generally attributed to natural sources, the potential of their contamination from anthropogenic sources cannot be excluded (Tahri et al., 2012), a characteristic example of which is iron. Despite the fact that this metal showed similar concentrations in the dust to those found in the background geological formations, magnetic analyses by Márton et al. (2011) showed the same characteristics for magnetite particles in the dust and in traffic-originated PM, suggesting that the major source of magnetite (and so the magnetite-derived $\mathrm{Fe}$ ) is vehicular traffic in this case.

The second group consisted of the other studied metals, which generally showed moderate enrichment in the dust. However, $\mathrm{Pb}$ and $\mathrm{Zn}$ showed heavy contamination in several cases. Ji et al. (2008) found that the total fraction of the UD $(<100 \mu \mathrm{m})$ exhibits practically similar metal concentrations to natural geological formations, while the fine fractions $(<10 \mu \mathrm{m})$ were mostly heavily enriched with $\mathrm{Cr}, \mathrm{Co}, \mathrm{Cu}, \mathrm{Pb}$, and $\mathrm{Zn}$ as shown by a study conducted on 15 Chinese cities. Literature data show that most of these metals may originate from traffic sources, but they are also the common components of the built environment (Sutherland, 2000).

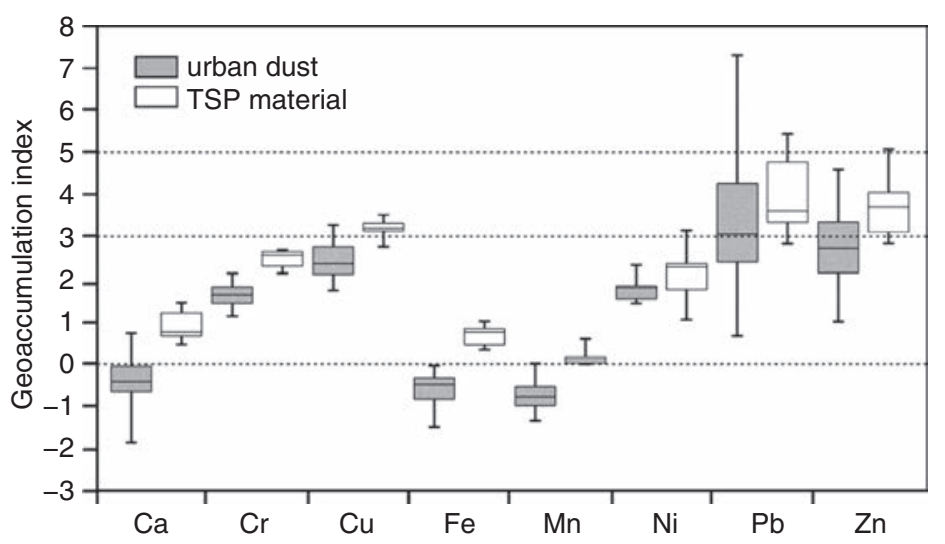

Figure 28.1 Comparison of the enrichment of selected metals in urban dust $(n=64)$ and TSP matter $(n=11)$ materials from Budapest, Hungary. Geoaccumulation index values were calculated after Ji et al. (2008). Values below zero refer to uncontaminated, those between zero and three to moderately contaminated, between three and five to heavily contaminated, and values over five extremely contaminated materials. 
Accumulation of metals in the dust exhibited both spatial and temporal variance (Sipos and May, 2013b). For example, $\mathrm{Cu}$ and $\mathrm{Zn}$ showed the highest enrichment at the high-traffic side and lower heights of the building as expected, whereas $\mathrm{Pb}$ could be characterised by high enrichment at the low-traffic side, too. Moreover, $\mathrm{Pb}$ and $\mathrm{Zn}$ may have shown strong enrichment even at $33 \mathrm{~m}$. On the other hand, the highest metal enrichments were found generally in the summer and spring samples. These characteristics, however, can be evaluated more effectively when metal deposition rates are considered, as the diluting effect of non-metal-bearing natural particles can be excluded (Sipos et al., 2014).

Both the seasonal and the vertical deposition of $\mathrm{Fe}, \mathrm{Cu}, \mathrm{Pb}$, and $\mathrm{Zn}$ showed large similarities to that of the dust. As this phenomenon was observed for each metal, it could not be explained by the changes in metal sources. The weather conditions favouring dust deposition and the increased rate of resuspended material in the dust in summer and spring may have affected the metal deposition together and result in its increase. Other studies, however, did not find any significant seasonal variation in metal deposition (Odabasi et al., 2002), or they found slightly higher values in the heating season (Krolak, 2000). In our case, however, the contribution of soil/dust resuspension was found to be the dominant source of the dust (primarily in the summer season) and may even overcome the effect of recent anthropogenic activities. Moreover, the resuspended material contains the contribution of past anthropogenic activities, which could have resulted in much higher metal concentrations than recent activities.

\subsubsection{Phase Composition of the Dust Material}

The major mineral components of the dust material reflected that of the geological background (Sipos et al. 2013d). Their most frequent components were found as follows: quartz $(60 \%-90 \mathrm{wt} \%)$, dolomite $(0 \%-20 \mathrm{wt} \%)$, calcite (0\%-15 wt\%), feldspar (5\%-10 wt\%), illite $(1 \%-5 \mathrm{wt} \%)$, chlorite $(1 \%-5 \mathrm{wt} \%)$, and occasionally smectite $(1 \%-5 \mathrm{wt} \%)$. These phases are the most common natural components of airborne PM (Farkas and Weiszburg, 2006) although both silicates and carbonates may also originate from anthropogenic sources (Zajzon et al., 2013). In the fine particle size fraction $(<20 \mu \mathrm{m})$, the ratio of clay minerals and amorphous materials significantly increased, and gypsum also appeared. This latter originated probably from the construction materials and/or the reaction of sulphuric acid and calcic material in the air (Panigrahy et al., 2003). The major mineral constituents of the UD samples identified by XRD were also observed by TEM analyses (Sipos et al., 2014). Using the latter technique, magnetite was also identified as a frequent component of the dust. This mineral often formed aggregates consisting of nanosized (up to $100 \mathrm{~nm}$ ) magnetite attached to large silicate particles, and was also present as relatively large (up to a few micrometres) spherular or xenomorphic polycrystalline particles. Magnetite was also identified as the only magnetic phase in the dust by magnetic analyses (Márton et al., 2011). These results showed that magnetite particles were present primarily as superparamagnetic $(<30 \mathrm{~nm})$ particles. Both its size and morphology suggested that this mineral originated primarily from anthropogenic sources (Zajzon et al., 2013). Additional iron minerals, such as hematite and ilmenite, were also found by TEM analyses but in much smaller amounts than magnetite. The most spectacular spatiotemporal variation in mineral ratios was found for the carbonate minerals (Sipos et al., 2014). Much higher dolomite ratios were found at the front of the building than at the back despite the presence of the dolomite hill behind the building. Due to the vicinity and morphology of the dolomite hill and the building, formation of a wake interface flow could be expected between them, resulting in the transport and deposition of the hill's material on the leeward (front) side of the building in an isolated separation bubble (Oke, 1988). The amount of carbonate 
minerals was generally higher in the periods of large dust deposition, which was also observed for clay minerals. This suggests a significant local source is resuspension of street dust and local soil. However, clay minerals were the only phases showing characteristic vertical differences in their deposition: their amount decreases with increasing sampling height at the back, and much more uniform pattern was found at the front of the building. The spatiotemporal variation in the clay mineral's deposition suggested the presence of remote sources in addition to local ones. These sources may have antagonistic effects at the different sides and levels of the building.

\subsubsection{Metal-Bearing Phases}

The most important potentially toxic metalbearing phases were found to be magnetite and clay minerals in the dust materials as shown by the TEM-EDS analyses by Sipos et al. (2012) and Sipos et al. (2014). Additionally, $\mathrm{Zn}$ was found to be associated with a calcite particle in one-single case. Zinc could be associated both with clay and Fe oxide particles (Figure 28.2a, c), while lead primarily to the latter particles (Figure 28.2b). The silicate and oxide particles often formed aggregates with each other. The $\mathrm{Zn}$ content of clay minerals could be as high as $5 \mathrm{wt} \%$, while Fe oxides were characterised by a slightly lower $\mathrm{Zn}$ content (up to $2.5 \mathrm{wt} \%$ ). The $\mathrm{Pb}$ content of the latter phases was generally between 2 and $3 \mathrm{wt} \%$, and they also contained a small amount of Mn (around 0.5 wt\%). Among Fe oxide particles, both magnetite and hematite were identified (Figure 28.2b). Additionally, ilmenite and titanite were also found in the samples, but they do not contain a significant amount of PTEs (except one ilmenite particle, which contained 0.5 wt $\% \mathrm{Mn}$ ). Urban anthropogenic particles are often enriched in toxic trace metals (Maher, 2009). Magnetite particles in the dust may have originated from the anthropogenic emissions, while clay particles may be derived rather from the resuspension of urban soils. Magnetite particles are resistant to weathering, releasing their toxic components slowly to the environment. However, its close association with hematite suggests its oxidation, which may proceed already in the anthropogenic combustion process as showed by the results of Zajzon et al. (2013), who found a close association between magnetite and hematite in vehicle exhaust materials. This latter phase is much less resistant than magnetite (Silva et al., 2007), and together with layer silicates (and carbonates), they could be the potential sources of mobile toxic metals in the dust material (Sipos et al., 2014).

Hierarchical cluster analysis based on the linear correlation between the metal deposition rates at the different sampling sites showed that $\mathrm{Cu}, \mathrm{Pb}$, and $\mathrm{Zn}$ showed slightly different spatiotemporal deposition characteristics (Sipos et al., 2014). Such differences in deposition patterns may have even suggested differences in host phases for the metals. The highest similarity was found for $\mathrm{Fe}$ and $\mathrm{Zn}$, and these two metals showed more similar deposition characteristics to $\mathrm{Pb}$ than to $\mathrm{Cu}$. This suggested that $\mathrm{Zn}$ and $\mathrm{Pb}$ may be associated with $\mathrm{Fe}$ at a higher proportion than $\mathrm{Cu}$.

\subsubsection{Suspended PM}

\subsubsection{Metals'Enrichment}

Concentrations and ranges of 16 chemical elements (with $\mathrm{Cd}, \mathrm{Cu}, \mathrm{Cr}, \mathrm{Ni}, \mathrm{Pb}$, and $\mathrm{Zn}$ among them being PTEs; see details in Sipos et al., 2013c) were found to be similar to those reported for street dusts (Sysalova and Szakova, 2006) and even for fine PM (Feng et al., 2009), although the general observation is that such elements tend to concentrate in the fine PM. This is, however, largely dependent on the prevailing local metal source as some of them may also emit largesized particles (Zajzon et al., 2013).

On the basis of the geoaccumulation index values of the studied PTEs, $\mathrm{Pb}, \mathrm{Zn}$, and $\mathrm{Cu}$ showed heavy contamination, whereas $\mathrm{Cr}$, $\mathrm{Cd}$, and Ni showed moderate contamination in the TSP material (Figure 28.1), suggesting 

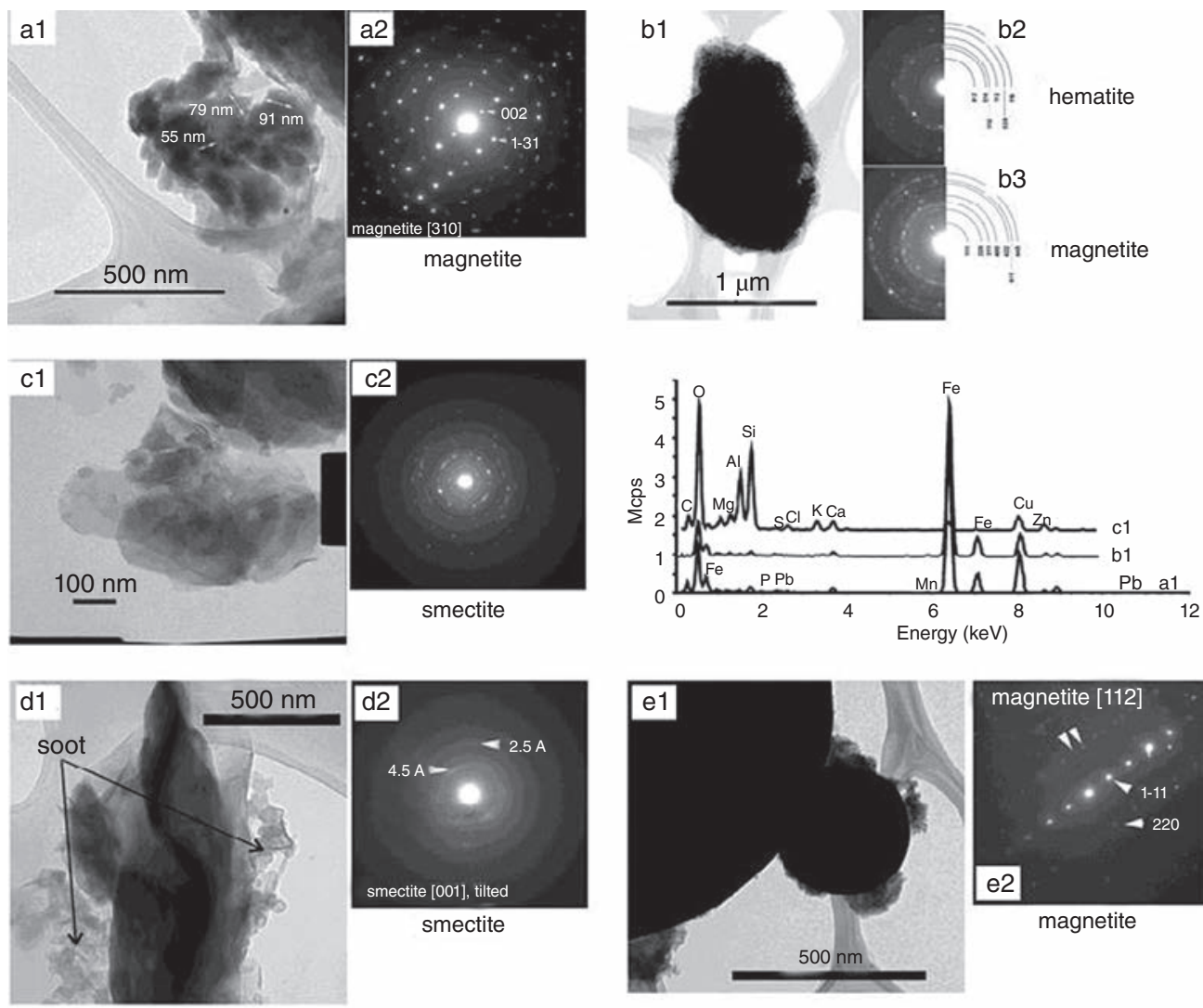

smectite
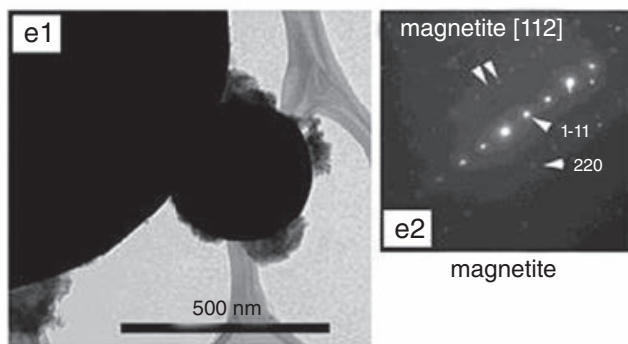

magnetite
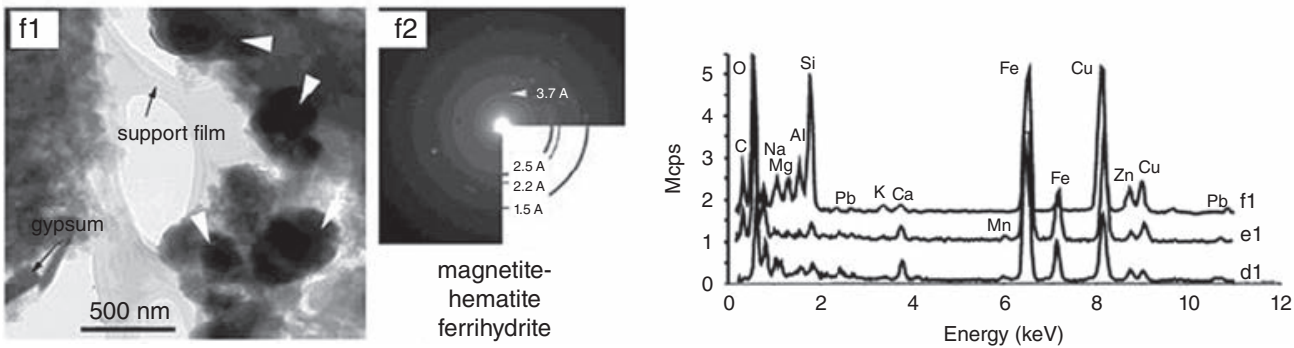

Figure 28.2 Transmission electron microscopy microphotographs (1) and electron diffraction patterns (2) of mineral particles observed in the urban dust $(a, b$, and $c)$ and suspended particulate matter ( $d$, e, and $f$ ) materials by TEM-EDS analyses: (a) an aggregate consisting of nano-sized magnetite single crystals with $2.49 \mathrm{wt} \% \mathrm{Zn}$ content; (b) a polycrystalline association of hematite and magnetite making up a large Fe oxide particle with $2.88 \mathrm{wt} \% \mathrm{~Pb}$; (c) relatively large smectite plates containing $4.89 \mathrm{wt} \% \mathrm{Zn}$; (d) smectite particle with $4.04 \mathrm{wt} \% \mathrm{Zn}$ and $0.41 \mathrm{wt} \% \mathrm{~Pb}$ associated with soot aggregates composed of nano-spheres; (e) magnetite spheres with $1.84 \mathrm{wt} \% \mathrm{Zn}$ and $2.38 \mathrm{wt} \% \mathrm{~Pb}$; (d) dense aggregates of magnetite, hematite (3.7 A) and poorly crystalline ferrihydrite with $2.55 \mathrm{wt} \% \mathrm{Zn}, 2.5 \mathrm{wt} \% \mathrm{~Pb}$, and $0.47 \mathrm{wt} \% \mathrm{Mn}$. Cu on the EDS spectra comes from the instrument.

the dominating presence of anthropogenic source(s) primarily for the former elements (Richter et al., 2007). The earliest studies on the metal concentrations in the TSP material from Budapest also found similar enrich- ment characteristics for the studied metals (Hlavay et al., 1996). Differences in metal concentrations and enrichments among the sampling sites suggest differences in the local metal sources there and/or in their distances 
as well, as local sources generally prevail for TSP material (Mateus et al., 2013). Salma et al. (2001) found that $\mathrm{Cd}, \mathrm{Cu}, \mathrm{Pb}$, and $\mathrm{Zn}$ exhibit very high enrichment both in coarse and fine PM in Budapest, Hungary, whereas $\mathrm{Cr}$ and $\mathrm{Ni}$ show moderate enrichment when compared to their crustal abundances. However, they showed also high variability among various sampling sites, which could be related to the variation of local sources. Kukkonen et al. (2003) estimated the relative contribution of source categories to ambient trace elements concentrations in the PM from Budapest. They found that substantial amounts of $\mathrm{Cd}, \mathrm{Pb}$, and $\mathrm{Zn}$ are originated from waste incineration $(65 \%-70 \%)$, whereas the contribution of traffic ranges from $11 \%$ to $17 \%$. Other sources (like coal or oil burning) account for $5 \%-7 \%$ additional contribution. Sipos et al. (2016) found that the highest $\mathrm{Zn}$ content in the TSP material may be related to the vicinity of a waste incinerator, as such objects are the major emission sources for several metals, especially for Zn (Liu et al., 2005). On the other hand, a high amount of $\mathrm{Pb}$ in some locations was related to vehicular traffic as busy road environment are huge reservoirs of former (but also of recent) $\mathrm{Pb}$ emission of traffic origin (Johansson et al., 2009). On the other hand, sampling points with low metal content could be related to the fact that they are placed next to the Danube River, which provides the major wind channel in Budapest.

\subsubsection{Phase Composition of PM}

The bulk mineralogical composition of the samples was dominated by the presence of minerals characteristic of the geological environment of the sampling sites (Sipos et al., 2013c). The samples consisted mostly of $15-20 \mathrm{wt} \%$ quartz, $5-20 \mathrm{wt} \%$ carbonates, $5-10 \mathrm{wt} \%$ clay minerals, and 5-10 wt\% (plagioclase) feldspar. Among the clay minerals, illite dominated, but chlorite and smectite also appeared. Such phases are characteristic natural components of UD, representing primarily the fraction depositing fast (Grobéty et al., 2010).
The relatively high loss on ignition values showed the presence of a large amount of volatile components. This could be primarily related to the presence of organic matter and soot, which was calculated to be between 14 and $25 \mathrm{wt} \%$ there. This also corresponded to the results of XRD analyses, with which large amounts of amorphous phases were identified. Transmission electron microscopic analyses also showed that soot aggregates consisting of nano-sized soot particles are common in this material. It is widely known (Grobéty et al., 2010) that soot is a common anthropogenic component of urban airborne $\mathrm{PM}$ as a result of different combustion (vehicle, heating, industrial, etc.) processes. Besides soot, the dominant anthropogenic phases in the samples were found to be the iron oxides, and gypsum and halite also appeared in large amounts occasionally (Sipos et al., 2013c). The XRD analyses showed the presence of large amounts of magnetite $(5-10 \mathrm{wt} \%)$ at most of the sampling sites. This phase was also shown by magnetic and TEM analyses together with ferrihydrite and hematite, but the frequency of the latter two phases was much lower than that of magnetite. They could be the oxidation/weathering products of magnetite. The oxidation may proceed already in the anthropogenic combustion process, as suggested by the results of Zajzon et al. (2013), who found a close association between magnetite and hematite in vehicle exhaust samples.

\subsubsection{Metal-Bearing Phases}

Both indirect and direct methods were used to study the metals' speciation in the TSP material. Hierarchical cluster analyses based on the linear correlation of the total concentrations of 16 elements showed that $\mathrm{Ca}, \mathrm{Sr}$, $\mathrm{Pb}$, and $\mathrm{S}$ can be probably related to carbonates and sulphates; $\mathrm{Fe}, \mathrm{Mn}, \mathrm{Cu}, \mathrm{Ni}$, and $\mathrm{V}$ to iron oxides; $\mathrm{Ba}$ to both of the former groups; and $\mathrm{K}, \mathrm{Rb}, \mathrm{Cr}, \mathrm{Ti}, \mathrm{Zn}$, and $\mathrm{Zr}$ to silicates and oxides (Sipos et al., 2013c). These results suggested that elements showing significant enrichment can be associated with different components with varying origin. 
Chemical extractions of PTEs and major chemical elements were also found to be useful in studying the potential host phases for metals (Sipos et al., 2016). Significant ratios (10\%-15\% of their totals) of $\mathrm{Zn}$ (and Cd) was found in water-soluble forms together with $\mathrm{Na}, \mathrm{K}, \mathrm{Mg}, \mathrm{Ca}$, and $\mathrm{S}$, forming mostly sulphates (and probable nitrates and chlorides, as well). Such phases may arise, for example, from the fly ash of fossil fuel combustion or waste incineration (Pinzani et al., 2002). The weak acid-soluble fraction mobilising carbonate bound and sorbed elements was also characteristic of $\mathrm{Zn}$ and $\mathrm{Cd}(40 \%-50 \%$ of the totals), suggesting that high mobility could be related to a large variety of potential phases. The strongly similar behaviour of $\mathrm{Zn}$ and $\mathrm{Cd}$ could be due to the common $\mathrm{Cd}$ impurities in $\mathrm{Zn}$ materials which seem to survive anthropogenic processes as well (Monaci et al., 2000). Although $\mathrm{Pb}$ and $\mathrm{Cu}$ showed lower fractionation in the easily soluble fractions (below $10 \%$ of their totals), our SEM-EDS analyses supported the presence of their water-soluble $\mathrm{Cu}$-sulphate; Figure 28.3e) and weakly acid-soluble (Pb sulphate; Figure 28.3d) forms in the TSP material. Additionally, TEM-EDS analyses showed that clay minerals (primarily smectites) also contained small amounts of $\mathrm{Pb}$ and $\mathrm{Zn}$ (up to a few wt\%) (Figure 28.2e). These metals are probably sorbed on the surface of clay minerals in the soil, whose resuspension may have contributed to the airborne PM, which is a well-documented phenomenon in the urban environment (Laidlaw and Filippelli, 2008).

The reducible fraction is expected to mobilise not only metal oxides dissolving at redox conditions but also metal carbonates susceptible to stronger $\mathrm{pH}$ drop (Fernandez et al., 2000). This fraction was mostly characteristic of $\mathrm{Pb}, \mathrm{Zn}$, and $\mathrm{Cd}(30 \%-50 \%$ of their totals) and partly for $\mathrm{Ca}, \mathrm{Cu}, \mathrm{Fe}, \mathrm{Mn}, \mathrm{Mg}$, and P. Mobilisation of $\mathrm{Fe}$ (and $\mathrm{Mn}$ ) suggested the presence of their hydroxides, whereas that of carbonates could be related to the appearance of $\mathrm{Ca}$ and $\mathrm{Mg}$ (but also of $\mathrm{Fe}$ and $\mathrm{Mn}$ ). Metal compounds, like sulphate, carbonate, and (hydr)oxide, are often found in emission sources including waste incineration and smelters in the urban environment (Sobonska et al., 1999). Our TEM analyses showed the occasionally close association of magnetite, hematite, and ferrihydrite (Figure 28.2f). This can be due to the weathering of resistant Fe oxides, and the presence of ferrihydrite can be related to the reducible fraction of metals and the release of the detected $\mathrm{Zn}, \mathrm{Pb}$, and $\mathrm{Mn}$ through the reducible extraction step. Also, a single particle of calcite containing $\mathrm{Pb}(4.88 \mathrm{wt} \%)$ and that of a smithsonite were also found by TEM, suggesting the presence of $\mathrm{Pb}$ and $\mathrm{Zn}$ in the form of (acidsoluble) carbonates. Such phases were found as a common component of urban airborne $\mathrm{PM}$, and their presence can be due to the contribution of fly ashes from fossil fuel combustion, waste incineration, or industrial (smelter) dust (Wichmann et al., 2000) to the urban airborne material.

Among the studied PTEs, $\mathrm{Cu}$ could be characterised by the highest association to organic matter in TSP on the basis of its large ratio (around $30 \%$ of the total) in the oxidisable fraction together with P. We observed the frequent presence of relatively large (several tens of micrometres) aggregates composing of silicates, Fe oxides, and organic matter as suggested by their high $\mathrm{P}$ and $\mathrm{S}$ content by SEM-EDS. Such aggregates often contained detectable amount $\mathrm{Zn}$ besides $\mathrm{Cu}$ (Figure 28.3c).

The residual fraction was dominated by elements composing of silicates and resistant oxides ( $\mathrm{Al}, \mathrm{K}, \mathrm{Mg}, \mathrm{Na}, \mathrm{Fe}$, and $\mathrm{Ti}$ ). The very high ratios of $\mathrm{Cr}$ and $\mathrm{Ni}$ (around $80 \%$ of the totals) in this, as well as in the aqua regia non-soluble fraction together with Fe suggest their association to magnetite. This phase is a widespread phase of anthropogenic origin in the airborne PM and exhibits high compatibility with these metals under various genetic conditions (Dare et al., 2014). Nevertheless, $\mathrm{Cu}$ and $\mathrm{Pb}$ exhibited a moderate fraction ( $40 \%$ of their totals), whereas $\mathrm{Zn}$ and $\mathrm{Cd}$ exhibited a small ratio $(10 \%-20 \%$ of their totals) in this fraction. Our SEM-EDS analyses showed the presence 
Figure 28.3 Backscattered electron images of PTE-bearing particles observed in the TSP material as studied by SEM-EDS: (a) an Fe oxide spherule with detectable $\mathrm{Cu}$ and $\mathrm{Zn}$ content (1) and a silicate aggregate containing $\mathrm{Cr}(2)$; (b) a silicate spherule with detectable $\mathrm{Pb}$ and Zn content; (c) an aggregate composing of silicates (grey particles), Fe oxides (bright particles), and probably of organic matter (as suggested by the large amount of $\mathrm{P}$ and $\mathrm{S}$ ) containing $\mathrm{Zn}$ and $\mathrm{Cu}$; (d) a particle composing of $\mathrm{Pb}$ and $\mathrm{S}$ (probably lead sulphate) (1) and a silicate particle containing $\mathrm{Zn}$; (e) a particle composing of $\mathrm{Cu}$ and S (probably copper sulphate) (1) surrounded by silicates (grey particles) and Fe oxide spherules (2).
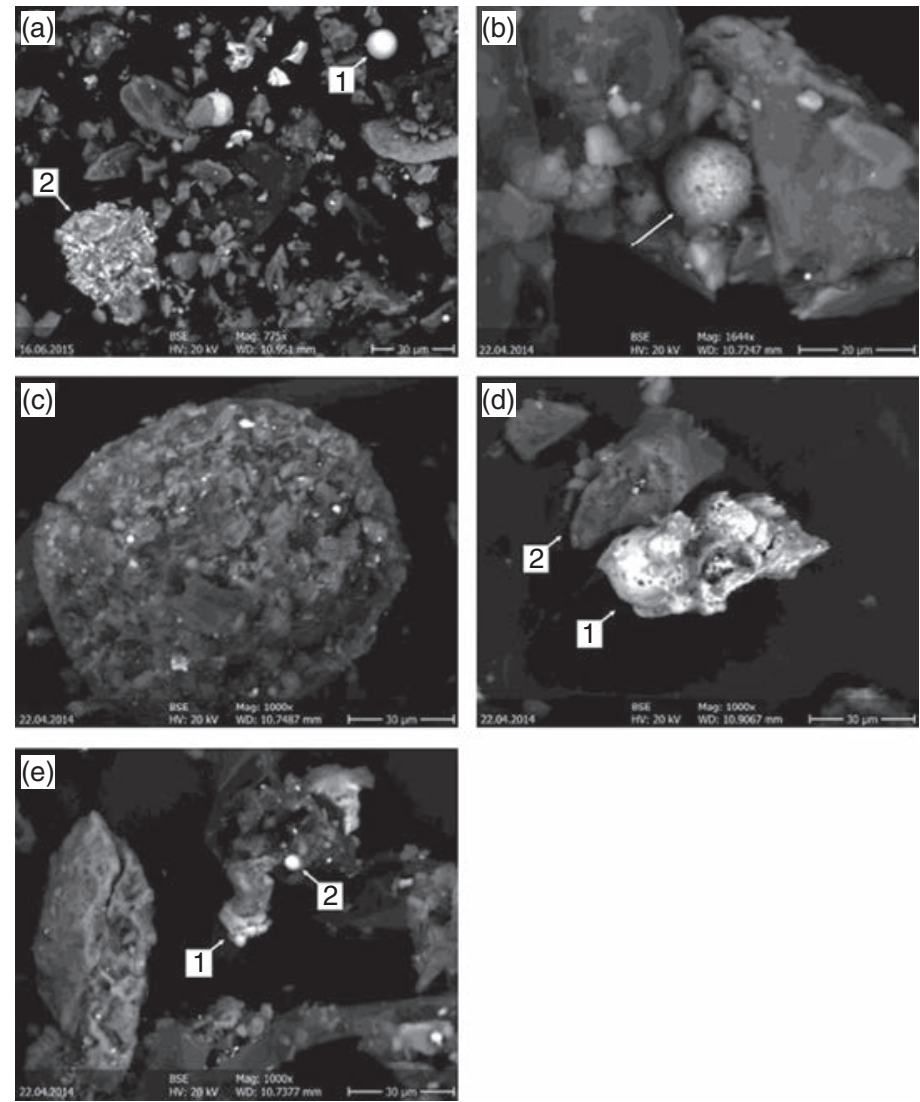

of both Fe oxide and silicate spherules, whose shape suggests their anthropogenic origin (Figure 28.3a, b). These particles often contained $\mathrm{Cu}, \mathrm{Zn}$ and $\mathrm{Pb}, \mathrm{Zn}$, respectively. Both spherular and xenomorphic magnetite particles were often found by TEM analyses as well, which were found to be the most important $\mathrm{Pb}$-bearing phases in the TSP material (Sipos et al., 2013a). They sometimes contain $2-3 \mathrm{wt} \%$ of $\mathrm{Pb}$ and $\mathrm{Zn}$ (and occasionally less $\mathrm{Mn}$ ) (Figure 28.2e, f). Several authors (e.g. Gautam et al., 2005) found a significant linear relationship between magnetic susceptibility (primarily due to magnetite) and the $\mathrm{Pb}$ content of urban PM. The magnetite particles often form aggregates and are closely associated with soot and/or clay minerals (Figure 28.2e). In samples with high magnetite content, metal-free magnetite spherules up to a few micrometres in size also appeared. Moreover, a single $\mathrm{ZnO}$ particle was also found in the sample with the highest $\mathrm{Zn}$ content, which could also contribute to the residual $\mathrm{Zn}$ fraction.

\subsection{Conclusions}

Several potentially toxic metals (like $\mathrm{Cu}, \mathrm{Pb}$, and $\mathrm{Zn}$ ) show moderate or even strong enrichment in the UD material when compared to their geochemical background. They are mostly of anthropogenic origin; however, this cannot be excluded for elements (like $\mathrm{Ca}, \mathrm{Fe}$ ) with no or slight enrichment either. Similar characteristics were found for the suspended PM, where metals with strong enrichment exhibit much higher concentrations. This phenomenon can be related to the small particle size of air pollutants of anthropogenic origin. 
On the basis of the metal deposition characteristics in the UD, resuspension of dust and soil, seasonal variation of weather, and the morphology of the natural and built environment affect the metal loading simultaneously, where all of these factors together may overcome the metal contribution from recent anthropogenic activities. In the suspended PM, however, the local anthropogenic sources showed a much higher effect on the type and concentration of metals, and the other factors mentioned for metals in UD dominate only in special cases.

The mineralogical composition is dominated by those from the geological environment for both types of material. As long as the anthropogenic phases are present at higher ratios among the major components of the suspended PM, they can be detected primarily in the fine fraction of the UD. Magnetite is their most frequent anthropogenic phase, but gypsum and soot are also often detectable. Not only the composition but the morphology of particles can be related to their origin, as spherules generally originate from anthropogenic sources. The ratio of natural phases in UD may supply additional information on the variation in the contribution of local and remote dust sources, supporting the evaluation of variation in metal deposition, as well.

The most important potentially toxic metal-bearing phases in the UD material are magnetite, clay minerals, and carbonates. Magnetite can be related to the contribution of (recent) anthropogenic activities; the presence of clay particles, however, can be due to the resuspension of urban soil after sorption of metals by them, resulting in metal contribution from former (inactive) anthropogenic sources. Such metal-bearing phases could also be observed in the suspended PM. Due to its higher metal concentrations and the combination of direct and indirect speciation analyses, however, more detailed characterisation of host phases could be provided. Mobile fractions (like water-soluble phases, metals sorbed on clay surfaces, metal carbonates) could be observed for each metal, showing strong enrichment in the suspended PM with primary significance for $\mathrm{Zn}$ and $\mathrm{Cd}$. Besides its carbonates, $\mathrm{Pb}$ could be associated with iron oxides, showing transformation or weathering from magnetite probably. Copper showed significant relation to the organic fraction of the suspended PM, although its detection with direct methods has failed. Very resistant phases, like magnetite and other metal oxides, contained the dominant proportion of $\mathrm{Cr}$ and $\mathrm{Ni}$, but significant amounts of $\mathrm{Pb}$ and $\mathrm{Zn}$ were also detected in such particles.

Iron and other metal oxide particles are relatively resistant to weathering, releasing their potentially toxic components to the environment slowly. On the other hand, water-soluble metal phases, metals sorbed on the surface of clay particles, and metal (containing) carbonates represent the potential sources of mobile components in the airborne PM. The transformation of magnetite to ferrihydrite observed in the suspended PM suggests that potentially toxic components associated with iron oxides cannot be considered exclusively immobile either.

\section{References}

Dabek-Zlotorzynska, E., Kelly, M., Chen, H., and Chakrabarti, C.L. (2003) Evaluation of capillary electrophoresis combined with BCR sequential extraction for determining distribution of $\mathrm{Fe}, \mathrm{Zn}, \mathrm{Cu}, \mathrm{Mn}$ and $\mathrm{Cd}$ in airborne particulate matter. Analitica Chimica Acta, 498, 175-187.
Dare, S.A.S., Barnes, S.J., Beaudoin, G., Meric, J., Boutroy, E., and Potvin-Doucet, C. (2014) Trace elements in magnetite as petrogenetic indicators. Mineralium Deposita, 49, 785-796.

Farkas, I. and Weiszburg, T. (2006.) Ülepedő és szálló por ásványtani vizsgálata a romániai 
Kolozs megyéből. Földtani Közlöny, 136, 547-572.

Feng, X.D., Dang, Z., Huang, W.L., and Yang, C. (2009) Chemical speciation of fine particle bound trace metals. International Journal of Environmental Science and Technology, 6, 337-346.

Fernandez, A.J., Ternero, M., Barragan, F.J., and Jimenez, J.C. (2000) A approach to characterization of sources of urban airborne particles through heavy metals speciation. Chemosphere, 2, 123-136.

Gautam, P., Blaha, U., and Appel, E. (2005) Magnetic susceptibility of dust-loaded leaves as a proxy of traffic-related heavy metal pollution in Kathmandu city, Nepal. Atmospheric Environment, 39, 2201-2211.

Grobéty, B., Gieré, R., Dietze, V., and Stille, P. (2010) Airborne particles in the urban environment. Elements, 6, 229-234.

Hlavay, J., Polyák, K., Bódog, I., Molnár, Á., and Mészáros, E. (1996) Distribution of trace elements in filter-collected aerosol samples. Fresenius Journal of Analytical Chemistry, 354, 227-232.

Huggins, F.E., Huffman, G.P., and Robertson, J.D. (2000) Speciation of elements in NIST particulate matter SRMs 1648 and 1650. Journal of Hazardous Materials, 74, 1-23.

Ji, Y., Feng, Y., Wu, J., Zhu, T., Bai, Z., and Duan, C. (2008) Using geoaccumulation index to study source profiles of soil dust in China. Journal of Environmental Sciences, 20, 571-578.

Johansson, C., Norman, M., and Burman, L. (2009) Road traffic emission factors for heavy metals. Atmospheric Environment, 43, 4681-4688.

Kim, K.H., Kabir, E., and Kabir, S. (2015) A review on the human health impact of airborne particulate matter. Environmental International, 74, 136-143.

Krolak, E. (2000) Heavy metals in falling dust in Eastern Mazowieckie province. Polish Journal of Environmental Studies, 9, 517-522.

Kukkonen, J., Bozó, L., Palmgren, F., and Sokhi, R.S. (2003) Particulate matter in urban air. In: Moussiopoulos, N. (ed.), Air Quality in Cities. Springer, Berlin, pp. 91-120.
Laidlaw, M.A.S. and Filippelli, G.M. (2008) Resuspension of urban soils as a persistent source of lead poisoning in children: A review and new directions. Applied Geochemistry, 23, 2021-2039.

Liu, F., Liu, J., Yu, Q., Jin, Y., and Nie, Y. (2005) Leaching characteristics of heavy metals in municipal solid waste incinerator fly ash. Journal of Environmental Science and Health A, 40, 1975-1985.

Maher, B.A. (2009) Rain and dust: Magnetic record of climate and pollution. Elements, 5 , 229-234.

Mateus, V.L., Monteiro, I.L.G., Rocha, R.C., Saint'Pierre, T.D., and Gioda, A. (2013) Study of the chemical composition of particulate matter from the Rio de Janeiro metropolitan region, Brazil, by inductively coupled plasma-mass spectrometry and optical emission spectrometry. Spectrochimica Acta Part B, 86, 131-136.

Márton, E., Sipos, P., Németh, T., and May, Z. (2011) Transport of pollutants around a high building: integrated magnetic, mineralogical and geochemical study. In: Conference Proceedings and Exhibitor's Catalogue, 6th Congress of Balkan Geophysical Society (3-6 October 2011, Budapest, Hungary), European Association of Geoscientists and Engineers, B9 1-6.

Monaci, F., Moni, F., Lanciotti, E., Grechi, D., and Bargagli, R. (2000) Biomonitoring of airborne metals in urban environments, new tracers of vehicle emission, in place of lead. Environmental Pollution, 107, 321-327.

Odabasi, M., Muezzinoglu, A., and Bozlaker, A. (2002) Ambient concentrations and dry deposition fluxes of trace elements in Izmir, Turkey. Atmospheric Environment, 36, 5841-5851

Ódor, L., Horváth, I., and Fügedi, U. (1997) Low-density geochemical mapping in Hungary. Journal of Geochemical Exploration, 60, 55-66.

Oke, T.R. (1988) Street design and urban canopy layer climate. Energy and Buildings, 11, 103-113.

Panigrahy, P.K., Goswami, G., Panda, J.D., and Panda, R.K. (2003) Differential 
comminution of gypsum in cements ground in different mills. Cement and Concrete Research, 33, 945-947.

Pinzani, M.C.C., Somogyi, A., Siminovici, A.S., Ansell, S., Steenari, B.M., and Lindovist, O. (2002) Direct determination of Cadmium speciation in municipal solid waste fly ash by synchrotron 22 radiation induced $\mu$-Xray fluorescence and $\mu$-X-ray absorption spectroscopy. Environmental Science and Technology, 36, 3165-3169.

Rauret, G., Lopez-Sanchez, J.F., Lück, D., Yli-Halla, M., Muntau, H., and Quevauviller, P. (2001) The certification of extractable contents (mass fractions) of $\mathrm{Cd}, \mathrm{Cr}, \mathrm{Cu}, \mathrm{Ni}$, $\mathrm{Pb}$ and $\mathrm{Zn}$ in freshwater sediment following a sequential extraction procedure. BCR information, Reference Materials BCR-701, European Commission, EUR 19775 EN.

Remeteiova, D., Smincakova, E., and Florian, K. (2007) Study of the chemical properties of gravitation dust sediments. Microchimica Acta, 156, 109-113.

Richter, P., Grino, P., Ahumada, I., and Giordano, A. (2007) Total element concentration and chemical fractionation in airborne particulate matter from Santiago, Chile. Atmospheric Environment, 41, 6729-6738.

Salma, I., Maenhaut, W., Zemplén-Papp, É., and Záray, G. (2001) Comprehensive characterisation of atmospheric aerosols in Budapest, Hungary: Physicochemical properties of inorganic species. Atmospheric Environment, 35, 4367-4378.

Seiler, H., Sigel, H., and Sigel, A. (1988) Handbook on Toxicity of Inorganic Compounds. Marcel Dekker Inc., New York.

Silva, M., Kyser, K., and Beauchemin, D. (2007) Enhanced flow injection leaching of rocks by focused microwave heating with in-line monitoring of released elements by inductively coupled plasma mass spectrometry. Analitica Chimica Acta, 584, 447-454.

Sipos, P., Kovács Kis, V., Márton, E., Németh, T., May, Z., and Szalai, Z. (2012) Lead and zinc in the suspended particulate matter and settled dust in Budapest, Hungary. European Chemical Bulletin, 1, 449-454.
Sipos, P., Németh, T., and Kovács Kis, V. (2013a) Lead isotope composition and host phases in airborne particulate matter from Budapest, Hungary. Central European Geology 56, 39-57.

Sipos, P. and May, Z. (2013b) Vertical distribution of metal deposition rates next to a major urban road in Budapest, Hungary. Carpathian Journal of Earth and Environmental Sciences, 8, 5-12.

Sipos, P., Márton, E., Németh, T., Kovács Kis, V., May, Z., and Szalai, Z. (2013c) Mineral phases containing heavy metals in the suspended dust from Budapest, Hungary. E3S Web of Conferences, 1: 20010.

Sipos, P., Németh, T., Kovács Kis, V., and Szalai, Z. (2013d) Seasonal and vertical variation of mineralogy and particle size distribution of settling dust along a high building. In: Zákányi, B. and Faur, K.B. (eds.), IX. Kárpát-mededncei Környezettudományi Konferencia (Miskolc, 2013. június 13-15), Miskolci Egyetem, Műszaki Földtudományi Kar, 499-504.

Sipos, P., Márton, E., May, Z., Németh, T., and Kovács Kis, V. (2014) Geochemical, mineralogical and magnetic characteristics of vertical dust deposition in urban environment. Environmental Earth Sciences, 72, 905-914.

Sipos, P., Choi, C., and May, Z. (2016) Combination of single and sequential chemical extractions to study the mobility and host phases of potentially toxic elements in airborne particulate matter. Chemie der Erde-Geochemistry. doi: 10.1016/j. chemer.2016.08.005

Sobonska, S., Riqo, N., Laboudigue, A., Bremard, C., Laureyns, J., Merlin, J.C., and Wignacourt, P. (1999) Microchemical investigation of dust emitted by a lead smelter. Environmental Science and Technology, 33, 1334-1339.

Sutherland, R.A. (2000) Bed-sedimentassociated trace metals in an urban stream, Oahu, Hawaii. Environmental Geology, 39, 611-627.

Sysalova, J. and Szakova, J. (2006) Mobility assessment and validation of toxic 
elements in tunnel dust samples - Subway and rod using sequential chemical extraction and ICP-OES/GF AAS measurements. Environmental Research, 101, 287-293.

Tahri, M., Bounakhala, M., Bout, A., Banyaich, F., Noack, Y., and Essaid, B. (2012) Application of nuclear analytical techniques (XRF and NAA) to the evaluation of air quality in Moroccan cities - Case of Meknes city. Carpathian Journal of Earth and Environmental Sciences, 7, 231-238.

Vardoulakis, S., Fisher, B.E.A., Pericleous, K., and Gonzalez-Fresca, N. (2003) Modelling air quality in street canyons: A review. Atmospheric Environment, 37, 155-182.

Wichmann, H., Spenger, R., Wobst, M., and Bahadir, M. (2000) Combustion induced transport of heavy metals in the gas phase: A review. Fresenius Environmental Bulletin, 9, 72-125.

Zajzon, N., Márton, E., Sipos, P., Kristály, F., Németh, T., Kovács Kis, V., and Wieszburg, T. (2013) Integrated mineralogical and magnetic study of magnetic airborne particles from potential pollution sources in industrial-urban environment. Carpathian Journal of Earth and Environmental Sciences, 8 (1), 179-186. 